\title{
Comparison of deferral rates using a computerized versus written blood donor questionnaire: a randomized, cross-over study [ISRCTN84429599]
}

\author{
John W Sellors*1,3,5, Robert Hayward 2,6, Graham Swanson 1 , Anita Ali ${ }^{4}$, R \\ Brian Haynes ${ }^{2}$, Ronald Bourque ${ }^{4}$, Karen-Ann Moore ${ }^{2}$, Lynne Lohfeld ${ }^{2,3}$, \\ Dawn Dalby ${ }^{3,7}$ and Michelle Howard ${ }^{1}$
}

Address: ${ }^{1}$ Department of Family Medicine (Room 2V9), McMaster University, 1200 Main Street West, Hamilton, Ontario, Canada, L8N 3Z5, ${ }^{2}$ Clinical Epidemiology and Biostatistics, (Room 2C Area), McMaster University, 1200 Main Street West, Hamilton, Ontario, Canada, L8N 3Z5, ${ }^{3}$ The Father Sean O'Sullivan Research Centre, St. Joseph's Healthcare, 105 Main Street, East Level P1, Hamilton, Ontario, Canada, L8N 1G6, ${ }^{4}$ Canadian Blood Services, 299 Main St. East Hamilton, Ontario, Canada L8N 1H8, 5 Present Address Program for Appropriate Technology in Health (PATH), 1455 NW Leary Way, Seattle, WA, USA, 98107, 6Present Address Department of Public Health Sciences, Clinical Health Sciences Bldg. Rm 13-103, University of Alberta, Edmonton, Alberta, Canada, T6G 2 G3 and 7Present Address University of Waterloo, Dept. Health Studies and Gerontology, 200 University Ave W, Waterloo, Ontario, Canada, N2L 39G

E-mail: John W Sellors* - jsellors@path.org; Robert Hayward - robert.hayward@cche.net; Graham Swanson - swansongr@yahoo.com; Anita Ali - jsellors@path.org; R Brian Haynes - bhaynes@mcmaster.ca; Ronald Bourque - bourque@cujo2.icom.ca; KarenAnn Moore - dmdalby@healthy.uwaterloo.ca; Lynne Lohfeld - lohfeld@mcmaster.ca; Dawn Dalby - kam@powersrfr.com; Michelle Howard - mhoward@mcmaster.ca

${ }^{*}$ Corresponding author

This article is available from: http://www.biomedcentral.com/I47I-2458/2//4

(C) 2002 Sellors et al; licensee BioMed Central Ltd. This article is published in Open Access: verbatim copying and redistribution of this article are permitted in all media for any non-commercial purpose, provided this notice is preserved along with the article's original URL.

\begin{abstract}
Background: Self-administered computer-assisted blood donor screening strategies may elicit more accurate responses and improve the screening process.

Methods: Randomized crossover trial comparing responses to questions on a computerized handheld tool (HealthQuiz, or $H Q$ ), to responses on the standard written instrument (Donor Health Assessment Questionnaire, or DHAQ). Randomly selected donors at 133 blood donation clinics in the area of Hamilton, Canada participated from 1995 to 1996. Donors were randomized to complete either the $H Q$ or the DHAQ first, followed by the other instrument. In addition to responses of 'yes' and 'no' on both questionnaires, the $H Q$ provided a response option of 'not sure'. The primary outcome was the number of additional donors deferred by the $H Q$.

Results: A total of 1239 donors participated. Seventy-one potential donors were deferred as a result of responses to the questionnaires; $56.3 \%(40 / 7 \mathrm{I})$ were deferred by the DHAQ, and an additional $43.7 \%$ ( $3 I / 7 I)$ were deferred due to risks identified by the HQ but not by the DHAQ. Fourteen donors self-deferred; II indicated on the $H Q$ that they should not donate blood on that day but did not use the confidential self-exclusion option on the DHAQ, and three used the selfexclusion option on the DHAQ but did not indicate that they should not donate blood on the HQ. The $H Q$ identified a blood contact or risk factor for HIVIAIDS or sexually transmitted infection that was not identified by the DHAQ in $0.1 \%$ to $2.7 \%$ of donors.
\end{abstract}

Conclusion: A self-administered computerized questionnaire may increase risk reporting by blood donors. 


\section{Background}

Infections in blood donors can be transmitted to blood product recipients. Strategies to reduce the risks to blood product recipients have involved public education programs, administration of questionnaires pertaining to HIV risk factors, the use of a confidential self-exclusion (CSE) option which allows the donor to indicate in a confidential manner that their blood should not be used for transfusion, and direct questioning about risk behaviours. These strategies have been found to eliminate some high risk $[1,2]$ and some infected units [3]. While there have been notable decreases in HIV-positive donations [4,5], some donors, who are aware of their high-risk behaviours continue to donate without self-deferral [3,6-9].

Serologic testing is now performed on all acceptable donors in Canada. In the past, window-period infections have been a concern, however the use of highly sensitive nucleic acid amplification technology (NAT) has now reduced this risk of a transfusion-transmitted infection due to a window-period donation to an estimated one per million donations or fewer in the U.S.[10,11]. In Canada,
NAT is used for HIV and HCV screening in blood donors ( [www.bloodservices.ca], accessed March 1, 2002).

Despite the small risk of infection from donated blood, there is strong public pressure to ensure that all measures to reduce the risk of transfusion-transmitted infection are used. A potential role for improved risk factor detection through pre-donation screening would be to reduce the risks from as yet unknown blood borne diseases if these diseases were associated with other known risk groups. Explicit direct questions instead of indirect references to high-risk behaviours for HIV/AIDS have been shown to increase self-deferral rates in donors at least two-fold $[12,13]$. It has been estimated that the standard donor health assessment questionnaire may miss as many as $10 \%$ of donors who engage in high-risk behaviours [6]. Studies using various computerized questionnaire methods have found increased reporting of perceived socially undesirable behaviors compared to face-to-face interviews in higher risk groups [14-17], however few have assessed the usefulness or acceptability of computer-assisted screening in the blood donation screening process $[18,19]$.

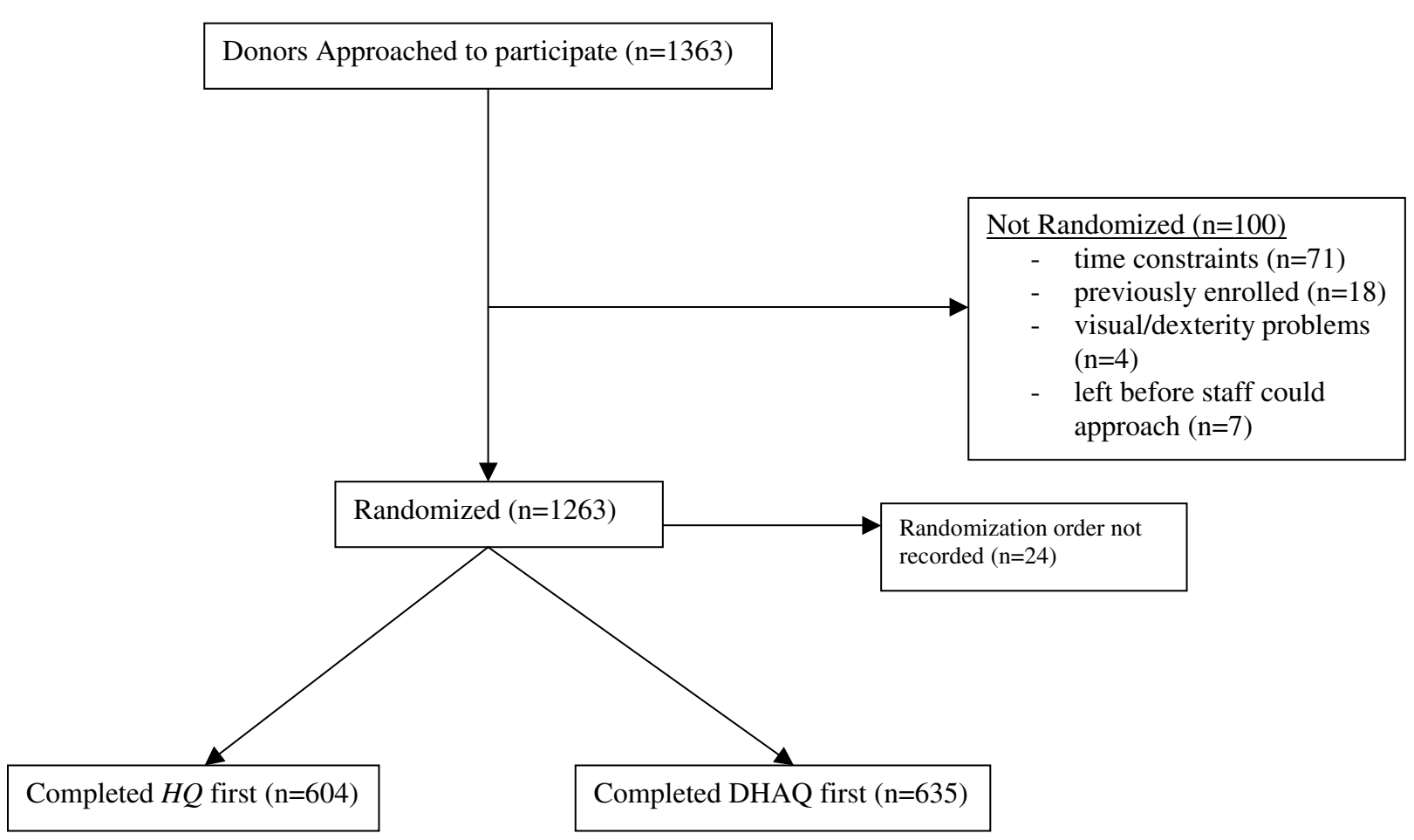

\section{Figure I}

Flow diagram of the randomized cross-over trial. 
This randomized crossover trial among blood donors compared a self-administered computerized questionnaire (HealthQuiz, or HQ) to the existing Donor Health Assessment Questionnaire (DHAQ) on consistency of responses. We also assessed the acceptability and ease of administration of the HQ in the donors.

\section{Methods \\ Participant enrolment}

The study was conducted at Canadian Red Cross Society (CRCS) blood donor events held at one of three clinic site types in the area of Hamilton, Ontario, Canada, from February 1995 to February 1996 ( $n=133$ events). Twentyfour $(18.0 \%)$ were held at a permanent clinic in Hamilton, $38(28.6 \%)$ at clinics within 30 minutes drive of the permanent clinic, and $71(53.4 \%)$ at clinics more than 30 minutes away.

At each event, the research staff used a list of random numbers that had been prepared earlier, to randomly select prospective donors who had been assigned an intake number in sequence by the CRCS staff. Potential subjects were greeted by study staff and invited to participate in completing the HQ in addition to the DHAQ. Those who agreed to be involved were randomly assigned to receive either the HQ followed by the DHAQ or the DHAQ followed by the HQ (Figure 1). The last digit of the participants' intake number was used to determine the order in which they received the questionnaire; an odd number indicated one order and an even number indicated the other order.

All participating donors received training on how to use the HQ. Donors were directed to one of the privacy booths for completion of both questionnaires. After finishing the first data collection method, subjects returned to the study personnel to receive the other method. Once both methods were completed, donors received a short satisfaction questionnaire that addressed issues regarding the acceptability and comfort level associated with using the HQ. After returning this questionnaire to study personnel, donors rejoined the queue to continue being processed for donation.

\section{Administration of questionnaires}

The HQ was presented on a 22.5 by $26.3 \mathrm{~cm}$ portable battery-operated computer that had been designed for questionnaire administration. The questions were developed using the standard written DHAQ. The questions appeared one at a time on a white high-contrast screen in black letters and were answered by the donor using one of three large buttons: 'yes', 'no', 'not sure'. Donors continued through the questionnaire by pressing the 'next question' button. The responses triggered a path through the branching questions. Pre-set algorithms created reports that were printed immediately and stored in a database. The printed report indicated that the donor should be accepted, deferred, or that further investigation was required by the clinic staff. In addition to the risk questions in the $H Q$, questions pertaining to the ease of use and readability of the HQ were asked.

At the time of the study, the DHAQ was a self-administered list of questions with 'yes' and 'no' boxes that are checked by the donors. Blood donor clinic staff reviewed the responses and decided if the donor should be accepted, deferred or questioned further. To conform to the usual clinic standards, donor acceptance or deferral was based on the responses to the DHAQ, reviewed by the clinic staff. However, if the research staff noted a potential deferral factor identified on the HQ, it was brought to the attention of the clinic staff. We did not gather specific information on the reason for deferral when deferral was based on the standard DHAQ. For the additional donors deferred because of a response on the HQ that was not identified on the DHAQ, the relevant items were noted.

Donors were given the opportunity to indicate on the DHAQ whether their unit should be used for transfusion by placing one of two stickers on their form; 'use my blood' or 'don't use my blood'. A question was asked on the HQ that gave donors an opportunity to indicate that there was a reason they should not donate blood on that day.

Donors who were accepted for donation had blood drawn for serology for HBsAg, HCV, VDRL, HTLV-1 and 2 and $\mathrm{HIV}$, using commercially available kits according to manufacturers' instructions.

The DHAQ responses were abstracted to a database by study staff, who were blind to other data, including the order in which the questionnaires had been presented. Ethical approval for the study was obtained from the McMaster University ethics review board.

\section{Statistical analysis}

The primary analysis compared the number of deferrals using the DHAQ compared to the additional number identified by responses to the HQ. Second, the responses to individual questions were compared between the two questionnaires. Due to evolving policies and procedures of the Canadian Red Cross Society, the DHAQ, and consequently the automated questionnaire were modified twice during the study period and sample sizes for various questions reflect this. McNemar's Chi-square was used to determine whether there were significant differences between the two questionnaires. A probability of a type I error (alpha) of 0.05 (two-tailed) was used to indicate statistical significance. 
Table I: Demographic characteristics of the I 239 blood donors randomized to the two orders of administration for the computerized HealthQuiz (HQ) and the written Donor Health Assessment Questionnaire (DHAQ).

HQ followed by DHAQ $(n=604) n(\%)$

DHAQ followed by $H Q(n=635) n(\%)$

Female gender

Annual household income $>\$ 24,000$

9 or more years of schooling

English spoken at home

Age (mean years, SD)
$47.7(288 / 604)$

$83.3(438 / 526)$

$95.9(561 / 585)$

$94.4(559 / 592)$

$33.9,14.7$
$54.5(346 / 635)$

$83.3(440 / 528)$

$95.0(584 / 615)$

$94.6(586 / 619)$

$34.1,14.5$
Table 2: The questions answered affirmatively to the computerized HealthQuiz that led to further investigation and deferral among 31 donors who would have been accepted using only the Donor Health Assessment Questionnaire for screening.

Item No. donors

In the last 3 days have you taken any type of medication

3 or drugs (pills, needles) except birth control pills or vitamins?

Taken Accutane in the past 12 months or Proscar, Danazol, or methotrexate ever?

Surgery in last 12 months

Ever had epilepsy, coma, stroke, repeated seizures, fainting

Ever had heart or blood pressure problems or heart surgery

Ever had kidney, lung, or blood condition

Been pregnant in the last 6 months or breast-fed in the last 3 months

Ever had yellow jaundice (other than at birth), hepatitis or liver disease

Received blood plasma, clotting factors or immune globulin in past 12 months

$\mathrm{Had}$ an AIDS test elsewhere (other than for donating blood)

\section{Results \\ Sample description}

Of the 1,363 donors approached, 1,263 (92.7\%) agreed to participate. The reasons given by the 100 non-participants are shown in Figure 1. Of the 1,263 participating donors, randomization order was not recorded for 24 , leaving 1,239 participants for analyses. There were 604 donors randomized to receive the HQ first and 635 were randomized to receive the DHAQ first (Figure 1).

Approximately half of the donors were women (634/ $1239,51.2 \%)$ and the mean age of the sample was 34.0 $(\mathrm{SD}=14.6)$ years. Eighty-three percent of the sample $(878 / 1054)$ reported an annual household income of over \$CA 24,000 (\$1 US = 1.5\$CA) and 95.4\% (1145/ $1200)$ had completed nine or more years of schooling. English was spoken at home by 94.5\% (1145/1211) of donors. The two randomized groups were similar on these characteristics (Table 1).

Ninety-six percent $(1184 / 1239)$ of the donors had donated at least once and $81.2 \%(1006 / 1239)$ had donated at least twice.

\section{Donor deferral}

Of the 1239 donors, 5.7\% (71/1239) were deferred based on the questionnaires. Items identified by the HQ nearly doubled the number of donors who were eventually deferred; $3.2 \%$ (40/1239) were deferred on the basis to their answers to the DHAQ reviewed by the clinic staff and an additional $2.5 \%(31 / 1239)$ were identified by items on the HQ which were not identified on the DHAQ. An additional 2.1\% (26/1239) were deferred because of low haemoglobin, and $0.2 \%(2 / 1239)$ changed their minds at bedside. There were no positive serologic tests to HBsAg, HCV, VDRL, HTLV-1 or 2, or HIV. The items on the HQ which led to the deferral of the additional 31 donors are shown in Table 2. Eight donors indicated used of medication, history of jaundice or hepatitis, receiving blood products, or having had an AIDS test outside blood donor screening, while the remaining 23 identified other items relating to their health history.

A total of 14 people used some form of self-exclusion option. Eleven people indicated that they had reason to think that they should not donate blood on that day on the HQ but did not use the CSE option on the DHAQ, and three donors self-deferred using the CSE option on the DHAQ but did not indicate that they should not donate blood on the HQ ( $\mathrm{p}=0.008)$. None of the 14 donors who used these options used it on both questionnaires.

\section{Response discrepancies between the HQ and the DHAQ} The frequency of discrepancies in which a response of 'yes' on one instrument changed to 'no' on the other, are 
Table 3: Discrepancies on responses (yes to no, or no to yes) between the HealthQuiz (HQ) and the Donor Health Assessment Questionnaire (DHAQ) among the 1239 study participants.

\begin{tabular}{|c|c|c|c|}
\hline Questions & $\begin{array}{l}\text { Risk identified } \\
\text { on HQ and } \\
\text { denied on } \\
\text { DHAQ n (\%) }\end{array}$ & $\begin{array}{l}\text { Risk identified } \\
\text { on DHAQ and } \\
\text { denied on HQ n } \\
(\%)\end{array}$ & $\begin{array}{l}\text { p value for } \\
\text { McNemar's Chi } \\
\text { square test }\end{array}$ \\
\hline
\end{tabular}

\section{Risk for HIVIAIDS or STDs}

Since 1977, have you participated in any of the activities that put one at risk for AIDS?*

Have you even once shared needles or taken street drugs by needle?

In the last 12 months have you had sex with someone who may have participated

in high-risk activities (sexual background uncertain)?

Have you had an AIDS test elsewhere (other than for donating blood)?

Had symptoms of AIDS? †

In the last I 2 months have you had a tattoo, ear-piercing, acupuncture, electrolysis, needle stick injury or graft?

Have you ever had yellow jaundice (other than at birth), hepatitis or liver disease? In the last 12 months to your knowledge have you come in close (intimate) contact with someone with yellow jaundice or hepatitis?

In the last 12 months have you received blood, plasma, clotting factors or immune globulin?

\section{Medication Use}

In the last 3 days have you taken any type of medication or drugs, except birth control pills or vitamins?

Have you taken Accutane or Tegison for a skin disorder or growth hormone (human pituitary)?

In the last month have you taken Accutane for a skin disorder, Proscar or Danazol?

\section{IIIness or exposure}

Are you free from cold, flu, infection or active allergy today?

Have you had a vaccination in the last 3 months or a rabies shot in the last year?

Have you had surgery in the last 6 months?

Have you had any of the following?

Epilepsy, coma, stroke, repeated seizures or fainting

Heart or blood pressure problems or heart surgery

Cancer, diabetes, ulcerative colitis or Crohn's disease

Kidney, lung or blood condition

Have you been pregnant in the last 6 months or breastfed in the last 3 months?

In the last 3 years have you lived in or visited an area where malaria is common?

\begin{tabular}{|c|c|c|}
\hline $4 /|2| I(0.3)$ & 0 & 0.13 \\
\hline $\mathrm{I} / \mathrm{I} 0 \mathrm{I}(0 . \mathrm{I})$ & 0 & 1.00 \\
\hline $29 / 1211(2.4)$ & $5 / 1211(0.4)$ & 0.001 \\
\hline $8 / 1239(0.6)$ & $13 / 1239(1.0)$ & 0.383 \\
\hline $34 / 1239(2.7)$ & $2 / 1239(0.2)$ & $<0.001$ \\
\hline $14 / 1216(1.2)$ & $8 / 1216(0.7)$ & 0.286 \\
\hline $17 / 1216(1.4)$ & 0 & $<0.001$ \\
\hline $1 / 1239(0.1)$ & 0 & 1.00 \\
\hline $36 / 1239(2.9)$ & I/I239 (0.I) & $<0.001$ \\
\hline $68 / 1239(5.5)$ & $27 / 1239(2.2)$ & $<0.001$ \\
\hline $7 / 1123(0.6)$ & 0 & 0.02 \\
\hline I/94 (I.I) & 0 & 1.00 \\
\hline $50 / 1239(4.0)$ & $3 / 1239(0.2)$ & $<0.001$ \\
\hline $12 / 1239(1.0)$ & $7 / 1239(0.6)$ & 0.36 \\
\hline $16 / 1239(1.3)$ & $4 / 1239(0.3)$ & 0.01 \\
\hline $21 / 1239(1.7)$ & $8 / 1239(0.6)$ & 0.02 \\
\hline $216 / 1239(17.4)$ & $3 / 1239(0.2)$ & $<0.001$ \\
\hline $17 / 1239(1.4)$ & $4 / 1239(0.3)$ & 0.007 \\
\hline 149/1239(12.0) & $4 / 1239(0.3)$ & $<0.001$ \\
\hline $3 / 1239(0.2)$ & I/I239 (0.1) & 0.625 \\
\hline $3 / 1239(0.2)$ & $\mathrm{I} / \mathrm{I} 239(0.1)$ & 0.625 \\
\hline
\end{tabular}

* these activities included: if male, having sex with another male, even once; sharing needles or taking street drugs by needle; receiving regular treatment with blood or blood products; being the sexual partner of someone who has taken part in any of the above activities or who has contracted AIDS or has tested positive for AIDS † the symptoms of AIDS included: weight loss, night sweats, fever, diarrhea or cough; lumps in the armpits, neck or groin, coloured patches on skin or inside mouth

shown in Table 3. Symptoms of AIDS were reported on the HQ but not on the DHAQ by $2.7 \%$ (34/1239) of donors $(\mathrm{p}<0.001)$ and $2.3 \%(29 / 1211)$ reported on the HQ but not on the DHAQ that they had had sex with someone who may have participated in high-risk activities $(\mathrm{p}<$ 0.001). The most common major discrepancy for the blood contact risk questions in which the risk was denied on the DHAQ but identified on the HQ was for receiving blood, plasma, clotting factors or immune globulin in the past 12 months $(2.9 \%, 36 / 1239, \mathrm{p}<0.001)$.

Other common major discrepancies, where a risk was reported on the HQ but denied on the DHAQ included a history of heart or blood pressure problems $(17.4 \%, 216 /$ 1239, ) and a history of a kidney, lung or blood condition $(12.0 \%, 149 / 1239)$ ( $p$ for both < 0.001).

In almost all cases where the 'not sure' option was chosen on the HQ, the response of 'no' had been chosen on the written DHAQ (Table 4). Symptoms of AIDS were denied on the DHAQ but answered 'not sure' by $2.3 \%$ (29/1239). The largest discrepancy for the blood contact risk questions occurred for having received blood, plasma, clotting factors or immune globulin in the last 12 months. This question was denied on the DHAQ but answered 'not sure' on the HQ by $4.8 \%(60 / 1239)$. Among the minor 
Table 4: Discrepancies on responses (yes to not sure, or no to not sure) between the HealthQuiz (HQ the Donor Health Assessment Questionnaire (DHAQ) among the 1239 study participants.

\begin{tabular}{lll}
\hline Questions & "Not sure" of risk on HQ and & Risk identified on DHAQ and \\
risk denied on DHAQ n (\%) & "not sure" of risk on HQ n (\%)
\end{tabular}

\section{Risk for HIVIAIDS or STDs}

In the last 12 months have you had sex with someone who may have participated in high risk activities (sexual background uncertain)?

Have you had an AIDS test elsewhere (other than for donating

blood)?

Had symptoms of AIDS?*

\section{Blood Contact Risk}

Have you ever had yellow jaundice (other than at birth), hepatitis, or liver disease?

In the last 12 months to your knowledge have you come in close (intimate) contact with someone with yellow jaundice or hepatitis?

\section{Medication Use}

In the last 3 days have you taken any type of medicine or drugs, except birth control pills?

Have you taken Accutane or Tegison for a skin disorder or growth hormone (human pituitary)?

In the last month have you taken Accutane for a skin disorder,

Proscar or Danazol?

\section{Illness or Exposure}

Are you free from a cold, flu, infection or active allergy today?

Have you had a vaccination in the last 3 months or a rabies shot in the last year?

Have you had surgery in the last 6 months?

Have you had any of the following?

Epilepsy, coma, stroke, repeated seizures or fainting

Heart or blood pressure problems or heart surgery

Cancer, diabetes, ulcerative colitis or Crohn's disease

Kidney, lung or blood condition

Have you been pregnant in the last 6 months or breastfed in the last 3 months?

Have you ever had malaria?

In the last 3 years have you lived or visited an area where malaria is common?

\begin{tabular}{|c|c|}
\hline $8 / 1211(0.7)$ & 0 \\
\hline $6 / 1239(0.5)$ & $2 / 1239(0.2)$ \\
\hline $29 / 1239(2.3)$ & 0 \\
\hline $2 / 1216(0.2)$ & 0 \\
\hline $7 / 1239(0.6)$ & 0 \\
\hline $13 / 1239(1.0)$ & $9 / 1239(0.7)$ \\
\hline $118 / 1 \mid 23$ (10.5) & 0 \\
\hline $7 / 94(7.4)$ & 0 \\
\hline $1 / 1239(0.1)$ & $4 / 1239(0.3)$ \\
\hline $28 / 1239(2.3)$ & $1 / 1239(0.1)$ \\
\hline $4 / 1239(0.3)$ & $3 / 1239(0.2)$ \\
\hline $9 / 1239(0.7)$ & $1 / 1239(0.1)$ \\
\hline $62 / 1239(5.0)$ & 0 \\
\hline $14 / 1239$ (1.1) & $1 / 1239(0.1)$ \\
\hline $23 / 1239(0.6)$ & 0 \\
\hline $7 / 1239(0.6)$ & $1 / 1239(0.1)$ \\
\hline $12 / 1239(1.0)$ & 0 \\
\hline $28 / 1239(2.3)$ & $1 / 1239(0.1)$ \\
\hline
\end{tabular}

* the symptoms of AIDS included: weight loss, night sweats, fever, diarrhoea or cough; lumps in the armpits, neck or groin, coloured patches on skin or inside mouth

discrepancies, the most common question denied on the DHAQ but answered 'not sure' on the HQ occurred for the question regarding taking Accutane or Tegison for a skin disorder, or taking a growth hormone $(10.5 \%, 118 /$ 1123). The remaining minor discrepancies of this type were reported in up to $5 \%$ of cases (Table 4).

\section{Acceptability of the HQ to donors}

The automated HQ was acceptable to a majority of the donors who responded to the questions, such that $82.7 \%$ $(1011 / 1222)$ reported that it was not difficult to use, $88.4 \%(1080 / 1222)$ did not have trouble reading the questions, and $86.1 \%(1053 / 1222)$ understood all of the questions. These responses were not associated with age, sex, education or previous donor experience (data not shown).

\section{Discussion}

Using the computerized $H Q$, the number of donors that were eventually deferred was nearly double the number that was deferred based on the written DHAQ, and eleven donors indicated on the computerized $H Q$ that there was some reason they should not donate blood on that day, but did not use the CSE option on the DHAQ. Risks related to blood-borne infections accounted for a small number of the items identified by the HQ that were not identified by the DHAQ, however the detection of even a small number of such individuals could potentially pre- 
vent a high risk donation. Although there were no seropositive donors in this study, the HQ identified additional donors who may have been at increased risk of acquiring a blood borne infection through various risk behaviours. The identification of high risk donors also has important implications for avoiding as yet unknown blood-borne infections.

Our finding, that the computerized HQ identified $2.4 \%$ of donors with risk factors for HIV/AIDS and sexually transmitted infections that were not identified on the written DHAQ is not unique. In a randomized crossover trial in the U.S., an additional $4.4 \%$ of donors with HIV risks or AIDS symptoms were identified when using a computerbased interview which asked about activities that place them at high risk for HIV, compared to the American Red Cross standard written questionnaire and interview [20]. Another study in the U.S. suggests that people may be more likely to respond truthfully about risk behaviours when questioning is anonymous [21]. In that study, a questionnaire mailed one to two months following a donation identified a risk factor that should have resulted in deferral of their donation among $2 \%$ of respondents. Of the respondents who reported risks only on the mailed survey, $8 \%$ of their donations had been rejected for transfusion due to a positive laboratory test.

Previous survey research on sexual behavior, smoking, alcohol, and drug use, has found that use of a computer-assisted questionnaire increased reporting of "stigmatized" behaviors compared to face-to-face interviews [14$17,22,23]$. However, some of these studies $[16,17,23]$ were limited by the lack of random allocation or randomized cross-over of the participants to the different screening methods, therefore it cannot be determined whether the differences in reporting were due to the different screening methods rather than differences in participants characteristics. In addition, all but one [22] of these studies were conducted in injection drug users at a needle exchange program, in gay men, and in women attending a sexually transmitted diseases clinic, therefore the results may not be generalizable to blood donor populations.

The finding in the present study that the computerized screening approach was feasible and acceptable to donors is similar to previous studies $[18,19]$. Comfort with the screening process and privacy of responses are important issues in eliciting accurate and honest responses. In a previous study, donors with unreported deferrable risk factors and with reactive infectious disease screening reported being more likely to disclose personal information to a computer [18].

A limitation of the present study and of other literature comparing two methods of self-reported information
$[15-17,22,23]$, was our inability to conclude that the HQ identified high-risk donors, in the absence of a gold standard. Since none of the donors in the present study were reactive for transmissible infections, we used deferral as a surrogate marker for high risk donors. Other studies in North America have also reported low rates of antibodies in blood donors. The sero-prevalence of HIV was $0.02 \%$ among 123,608 Canadian donors during 1985 [6] and was $0.03 \%$ in the U.S. among blood donors in 1995 [21]. Despite the current low seroprevalence of infections in blood donors in North America, a recent study has found that new cases of HIV, HCV, and HBV were as common among frequent donors as among infrequent donors [24], suggesting that caution must still be used in blood donor screening strategies.

Previous research has suggested that the limitations of screening questionnaires in identifying ineligible donors may in part be due to the donors' failure to carefully read the instructions or understand the information [8]. In one study, some HIV-positive donors failed to exclude their donated units because of difficulty understanding the written explanation of the self-exclusion process [25]. While it may be that donors were more willing to disclose facts that made them ineligible for blood donation on a computerized questionnaire, other factors could have influenced the responses. Most of the donors were repeat donors and were familiar with the written DHAQ questions and format. Therefore, some donors may not have read the questions carefully, leading to inaccurate answers. The items for which the largest number of donors answered negative on the DHAQ but positive on the HQ were items which had multiple individual questions on the HQ but were listed in one question on the DHAQ. The high frequency of reporting on the HQ for items such as having heart or blood pressure problems or heart surgery (17.4\%), and a kidney, lung or blood condition $(12.0 \%)$ is surprising and suggests that some donors may not have understood or carefully read these questions. Affirmative answers to these questions on the DHAQ would have led to further review of the responses with the clinic staff and would have likely resulted in changes to the responses, otherwise the deferral rate would have been much higher. Without further staff investigation, healthy risk-free donors could mistakenly be deferred if questions on a selfadministered questionnaire are not understood. These results highlight the need for careful evaluation of a computerized screening process to ensure that accurate information is obtained without burdening clinic staff.

A computerized questionnaire may improve the efficiency of the donor screening process. The computer was easy to use and the data that were entered into the computer were immediately available as a printed report and in electronic medium for storage. Transcription errors were eliminated 
and the database was complete for each potential donor. A limitation of this study was the inability to compare the efficiency of the deferral process using the $H Q$ to the usual process using the written instrument, since no information regarding staff resources was obtained.

In response to the increasingly complex and time-consuming donor screening process, computer-assisted screening is currently in place in some areas, and the U.S. Food and Drug Administration (FDA) has recently provided draft guidelines for the use of self-administered questionnaires including those that are computer-assisted $[26,27]$. The FDA recommends assessment of the effectiveness of self-administered questionnaires in identifying unsuitable donors. The randomized cross-over trial is a useful methodology for this type of assessment, both to identify unclear or problematic questions and to have a valid comparison of responses to the two methods within each individual. Studies presenting different testing methods to different individuals, especially in a non-randomized fashion, cannot provide such comparisons.

While the risk to blood product recipients of contracting infections from blood products has been dramatically reduced with the use of new diagnostic technologies, this study suggests that it may be possible to further improve the blood donor screening process. In addition to excluding high-risk donors, donor health assessment is carried out to include healthy risk-free donors and to protect individuals with medical conditions from possible adverse effects of donating. While we cannot conclude that the increased number of deferrals and risk factors identified in this study resulted in an improvement in the donor screening process, a computerized instrument may have the potential to improve this process if more truthful answers are elicited.

\section{Competing Interests}

None declared

\section{Authors' Contributions}

JWS contributed to the study conception and design and critically revised the manuscript, RH and GS contributed to the study conception and design and in the analysis and interpretation of the data, AA contributed to the study conception and design and acquisition of the data, RBH contributed to the study conception and design and critically revised the manuscript, RB contributed to acquisition and in the analysis and interpretation of the data, KAM contributed to the analysis and interpretation of the data, LL contributed to the acquisition of the data, DD contributed to analysis and interpretation of the data, and $\mathrm{MH}$ contributed to analysis and interpretation of the data and critically revised the manuscript.
All authors have read and approved the final manuscript.

\section{Acknowledgments}

This study was supported by a research grant from the Bayer Blood Partnership Fund, Toronto, Ontario, Canada

We would like to thank Marg Pauls, the study nurse, for assistance with recruiting participants at the blood donor clinics.

\section{References}

I. Pindyck J, Waldman A, Zang E, Oleszko W, Lowy M, Bianco C: Measures to decrease the risk of acquired immunodeficiency syndrome transmission by blood transfusion. Evidence of volunteer blood donor cooperation. Transfusion 1985, 25:3-9

2. Perkins HA, Samson S, Busch MP: How well has self-exclusion worked? Transfusion 1988, 28:601-602

3. Petersen LR, Doll LS, White CR, Johnson E, Williams A: HIV Blood Donors Study Group. Heterosexually acquired human immunodeficiency virus infection and the United States blood supply: considerations for screening of potential blood donors. Transfusion 1993, 33:552-557

4. Lewis WF, Dodd RY: Trends in prevalence of HIV infection among U.S. blood donors. Transfusion 1992, 32(S):56S

5. Glynn SA, Kleinman SH, Schreiber GB, Busch MP, Wright DJ, Smith JW, Nass CC, Williams AE: Trends in incidence and prevalence of major transfusion-transmissible viral infections in US blood donors, I99 I to 1996. JAMA 2000, 284:229-235

6. Belcher LO, Chandler LK, Gilcher RO: Confidential unit exclusion - is it effective? Transfusion 1989, 29(S):76S

7. Chiavetta JA, Nusbacher J, Wall A: Donor self-exclusion patterns and human immunodeficiency virus antibody test results over a twelve-month period. Transfusion 1989, 29:8I-83

8. Doll LS, Petersen LR, White CR, Ward JW, and the HIV Blood Donor Study Group: Human immunodeficiency virus type I-infected blood donors: behavioral characteristics and reasons for donation. The HIV Blood Donor Study Group. Transfusion 199I, 31:704-709

9. Petersen LR, Doll LS, and the HIV Blood Donor Study Group: Human immunodeficiency virus type I-infected blood donors: epidemiologic, laboratory, and donation characteristics. Transfusion 1991, 3 I:698-703

10. Busch MP: HIV, HBV, and HCV: new developments related to transfusion safety. Vox Sang 2000, 78:253-256

II. Busch MP, Kleinman SH: Nucleic acid amplification testing of blood donors for transfusion-transmitted infectious diseases. Transfusion 2000, 40: I43-159

12. Mayo DJ, Rose AM, Matchett SE, Hoppe PA, Solomon JM, McCurdy KK: Screening potential blood donors at risk for human immunodeficiency virus. Transfusion 1991, 3 I:466-474

13. Gimble JG, Friedman LI: Effects of oral donor questioning about high-risk behaviors for human immunodeficiency virus infection. Transfusion 1992, 32:446-449

14. Lessler JT, O'Reilly JM: Mode of interview and reporting of sensitive issues: design and implementation of audio computerassisted self-interviewing. NIDA Res Monogr 1997, 167:366-382

15. Kissinger P, Rice J, Farley T, Trim S, Jewitt K, Margavio V, Martin DH: Application of computer-assisted interviews to sexual behavior research. Am J Epidemiol 1999, 149:950-954

16. Metzger DS, Koblin B, Turner C, Navaline H, Valenti F, Holte S, Gross $\mathrm{M}$, Sheon A, Miller H, Cooley $\mathrm{P}$, et al: Randomized controlled trial of the audio computer-assisted self-interviewing utility and acceptability in Iongitudinal studies. Am J Epidemiol 2000, 1 52:99-106

17. Newman JC, Des Jarlais DC, Turner CF, Gribble J, Cooley P, Paone $D$ : The differential effects of face-to-face and computer interview modes. Am J Public Health 2002, 92:294-297

18. Watanabe KK, Zuck T, Schreiber GB, Biswas B, Williams AE: Computerized donor screening strategies: perceived advantages and disadvantages among blood donors. Transfusion 2000, 40(suppl): $4 \mathrm{~S}$

19. Zuck TF, Cumming PD, Wallace EL: Computer-assisted audiovisual health history self-interviewing. Results of the pilot study of the Hoxworth Quality Donor System. Transfusion 200I, $4 \mid$ : |469-| 474 
20. Locke SE, Kowal off HB, Hoff RG, Safran C, Popovsky MA, Cotton D, Finklestein DM, Page PL, Slack WV: Computer-based interview for screening blood donors for risk of HIV transmission. JAMA | 992, 268:130|-|305

21. Williams AE, Thomson RA, Schreiber GB, Watanabe K, Bethel J, Lo A, Kleinman SH, Hollingsworth CG, Nemo GJ: Estimates of infectious disease and risk factors in US blood donors. JAMA I997, 277:967-972

22. Wright DL, Aquilino WS, Supple AJ: A comparison of computerassisted and paper-and-pencil self-administered questionnaires in a survey on smoking, alcohol, and drug use. Public Opin $Q 1998,62: 331-353$

23. Des Jarlais DC, Paone D, Milliken J, Turner CF, Miller H, Gribble J, Shi $\mathrm{Q}$, Hagan $\mathrm{H}$, Friedman SR: Audio-computer interviewing to measure risk behaviour for HIV among injecting drug users: a quasi-randomised trial. Lancet 1999, 353:1657-1662

24. Schreiber GB, Glynn SA, Busch MP, Sharma UK, Wright DJ, Kleinman $\mathrm{SH}$ : Incidence rates of viral infections among repeat donors: are frequent donors safer? Transfusion 200I, 41:730-735

25. Leitman SF, Klein HG, Melpolder J], Read EJ, Esteban JI, Leonard EM, Harvath L, Shih HW, Nealon R, Foy J: Clinical implications of positive tests for antibodies to human immunodeficiency virus type I in asymptomatic blood donors. N Engl J Med 1989, 321:917-924

26. U.S. Department of Health and Human Services. Food and Drug Administration, Center for Biologics Evaluation and Research (CBER): Guidance for industry. Streamlining the donor process: recommendations for self-administered questionnaires. Draft Guidance. [www.fda.gov/cber/gdlns/donorsaq.htm]

27. Rogenski LL, Katz L: Audio-video computer assisted self interview (CASI) of blood donors. Transfusion 200I, 4 I (suppI): I24S

\section{Pre-publication history}

The pre-publication history for this paper can be accessed here:

http://www.biomedcentral.com/1471-2458/2/14/prepub

Publish with BioMed Central and every scientist can read your work free of charge

"BioMedcentral will be the most significant development for disseminating the results of biomedical research in our lifetime."

Paul Nurse, Director-General, Imperial Cancer Research Fund

Publish with BMC and your research papers will be:

- available free of charge to the entire biomedical community

- peer reviewed and published immediately upon acceptance

- cited in PubMed and archived on PubMed Central

- yours - you keep the copyright

Submit your manuscript here:

http://www.biomedcentral.com/manuscript/
BioMedcentral.com editorial@biomedcentral.com 